\title{
Model of brand value management as a process of strategic increase of enterprise value
}

\author{
Vasyl Porokhnya*, Olena Kravets, Anastasiia Didenko, and Vladyslav Penev \\ Classical private university, Zaporizhzhia, 69061, Ukraine
}

\begin{abstract}
Constantly increasing the level of competition requires manufacturers of goods and services to individualize their products. Considering this factor, the brand takes on a new level of perception, a level of the strategic asset of the company, which allows evaluating the value of the company. With the pursuit of competitiveness and modernity, domestic companies have only in the last few years begun to view the brand as an integral part of their business, capable of generating additional profits at the expense of increased consumer loyalty. However, there are currently no standard methods for evaluating brand value, and there are some disadvantages to applying them. The article deals with modern research methods of the Interbrand and V-RATIO brand. It is revealed that the results of the calculations by different methods differ depending on the set goal: long-term or short-term costs. 19 brand evaluation criteria are considered. We propose our conceptual model of brand value estimation based on a closed system of factor analysis and modeling. The impact of the criteria on the choice of alternatives for choosing brand value strategies is suggested to be found by the Saati hierarchy analysis method. To enhance the adaptive properties of the selected criteria, it is proposed to use the mechanism of alternative strategies for increasing brand value by incorporating the Kohonen neural network process algorithm. The structure of hierarchies of influence of defined criteria on the brand development scenarios was constructed. Calculations were made by the method of analysis of hierarchies in the author's developed system, and it was found that having the resources to increase only one criterion of brand development would be the best development of leadership or internationality of the company. Based on the calculations neural network in the MATLAB, it was found that enterprise, which was researched, needed to pay attention to advertising costs or to increase brand value.
\end{abstract}

\section{Introduction}

Today's economy is changing rapidly, so the impact of the brand on value added can sometimes play not just an important but also a fundamental role. Because of this fact, every modern enterprise that wants to be competitive in the market should have a strategy to develop its brand. Brand development can be done for different purposes: to increase value added, to sell, to the franchise, etc. For each goal, you can choose a specific development method and apply it to the desired values, but sometimes it is very difficult to determine the purpose, evaluation criteria and overall object of evaluation to obtain the desired result.

There are many different studies around the world to study brand valuation methods, but none of them has become a benchmark. This problem is very relevant for Ukrainian enterprises because the interest of domestic entrepreneurs in the study of brand value is minimal. If large business executives are thinking about brand development, then small and medium-sized business representatives are not sufficiently aware of the potential benefits of brand implementation.
It is especially difficult to estimate brand value because of uncertainty about the concept of "brand", as well as the many factors that affect its value due to lack of standards. For example, D. Shevchenko, wrote [1]: "A brand is a sign, symbol, words or their combination, phrases that identify and help consumers distinguish goods, services, companies from competitors". Instead, J. Gregory, founder of the consulting firm CoreBrand, described the brand as the sum total of a person's experience, perception of things, products, company or organization. A brand is not the thing itself, not the product itself, not the company or organization itself. Brands do not exist in the real world - they are mental constructions. Brands exist in the form of consciousness or of specific people or society [2]. In turn, D. Ogilvy, founder of Advertising Agencies, made the following definition of a brand: "A brand is an elusive sum of the properties of a product: its name, packaging and price, its history, reputation, and advertising style. A brand is also a combination of the impression it makes on consumers and the result of their experience in using the brand" [3]. Peter Doyle, consultant for Coca-Cola, Shell, IBM, gave the following definition of branding [4]: "A brand is an aggregate that consists of both a product that

\footnotetext{
* Corresponding author: vprhnp76@gmail.com
} 
satisfies the functional needs of consumers and an added worth that drives consumers to feel more satisfied with by forming a belief that this brand is of a higher quality or more desirable to them than similar brands offered by competitors". Thus, authors of different models and techniques interpret the concept of "brand" in their sole discretion. In this regard, many studies have some uncertainties in the application of the techniques and the number of such works increases over time. Based on the definitions of other authors and the specific task, we will give our own definition of brand. If you delve into the etymology of the concept, you can understand that the brand meant "stigma". So, we will perceive the brand as a set of design decisions, advertising photos and video works, planned interactions with the consumer, which aims to build the reputation of the company, leaving the "stigma". The article [5] states that there are two levels of brand value: current and appropriable. For each business, these parameters may vary, as they are subjective parameters that depend on the resources and capabilities of the target audience. The current level of value is based on projected profit, and the appropriable level can be obtained by the company provided the effective use of available brand equity.

There are two international standards of brand assessment. The first ISO 10668:2010 "Brand valuation - Requirements for monetary brand valuation" was developed and approved in 2010 [6]. The 2010 standard establishes that when evaluating brand value, three aspects must be considered: financial, behavioral and legal. The legal aspect should include a clear definition of the concept of "brand" and the intellectual property law that is associated with it. The behavioral aspect includes an analysis of the behavior of all participants in business processes in the geographical, product and consumer segments of the market if there is a brand. The financial aspect considers three alternative approaches to assessing brand value: income, market, and cost. Estimating brand value using an income approach examines the brand life cycle and the economic effect that can be obtained from the brand in the future. With this approach, the net present value is calculated; it includes the amount of future discounted net profit flows that will be received when using the brand, that is, the cash flow difference in the presence and absence of the brand. The market approach is based on determining the expected price at which the brand can be sold in the free market. With this approach, similar brands are selected that are comparable in terms of brand strength and market position of goods and services. The cost approach can be used to calculate the minimum indicator of brand value, it consists in determining the amount to invest in creating and developing a brand for a nonbrand product to achieve the same market position as the brand being evaluated. The second standard ISO 20671:2019 - "Brand evaluation - Principles and fundamentals" contains technical requirements and methods that are used to evaluate a brand; also he forms a holistic approach to brand valuation, which includes the non-financial and financial aspects of valuation, and is a benchmark for the development and implementation of other brand evaluation and brand valuation standards [7].

Among the many modern techniques used in practice are the following: Interbrand [8], V-RATIO [9], FutureBrand [10], BBDO Consulting [11], BrandFinance [12], Damodaran's Model [13], Consor [14] and other.

The results of studies of these methods vary greatly depending on the goal, as well as internal and external conditions. For example, if a company work for a longterm perspective and at the moment sales are low or are falling and profitability is negative, then the Interbrand method is valued at a low level, while the V-RATIO method considers long-term prospects, which significantly changes the conclusions.

Scott M. Davis developed 19 different criteria for brand assessment [15]. Each of the criteria is optional and different companies choose the most relevant criteria for evaluating their brand. Based on the analysis of the frequency of use of certain criteria, eight benchmarks were eventually selected, which were named ROBI 8 (Return on Brand Investment) [15].

Consider 19 criteria developed by Scott M. Davis:

1. Recognition that is the ability of the consumer to remember the brand and distinguish it from competitors.

2. Understanding the brand position, that is, the degree of consumer understanding of the organization's position and the essence that it wants to convey to the target audience while introducing the brand.

3. Fulfillment of obligations implies compliance of the brand with the expectations of consumers and the fulfillment of the promises made to them.

4. Brand identity is rated as the degree of brand uniqueness, its constituents, compared to its competitors.

5 . The level of associations involves the definition of criteria that allow you to evaluate the positioning of the brand and the vector of its action on the pyramid of values.

6. The number of consumers attracted by the brand.

7. The number of lost buyers, that is, the number of consumers who have abandoned the products of a given brand to the side of competitors or, in general, to purchase products in the industry.

8. Market share is the ratio of the number of consumers who use the brand's products to the total number of potential consumers.

9. Current market penetration is estimated as the number of additional goods and services that can be sold to actual buyers due to the strength of the brand of the company.

10. Buyers' loyalty to the brand's products and the amount of time they consume the brand's products.

11. The degree of influence of the brand of the company on the frequency of purchases of goods of the selected category.

12. The public interest is determined by the number of positive reviews in the Media, social networks about the brand.

13. Respect for a brand is the opinion of consumers about it and how they describe it in conversations with other people. 
14. Indicator of recommendations is the percentage of new purchases made through recommendations from another buyer.

15. Customer satisfaction is an assessment of the degree of customer satisfaction with contact with a branded product or service.

16. Financial value is the market value of a brand in monetary terms.

17. The price premium is defined as the most permissible percentage of the price of a particular brand's goods in comparison with the products of competing brands.

18. Advertising profitability is the financial return on advertising costs.

19. Buyer's trust value. The buyer's trust parameter shows how important it is to maintain brand loyalty in buyers, and how it will affect other brand advocates.

The qualitative characteristics of ROBI 8 include the following [15]:

1. Brand Awareness. To obtain results by this criterion, surveys are conducted similar to those conducted by advertising campaigns to obtain the results of their activities. Respondents are asked about the brand and are tested for both complete and comprehensive results with both answer options and open-ended questions.

2. Understanding brand position. Surveys among consumers who use products or abandon a given brand, which clarifies the consumer's opinion on the positioning of the brand. Brand positioning should be in line with the view of the target audience.

3. Criteria that indicate an individual brand identity, often coinciding with strong brand features. Most often, the brand identity that the company management sees does not match the opinion of the target audience.

4. Brand commitment. How far brand positioning and the promises made to them correspond to the real state of brand engagement with the consumer.

Based on the interaction of the consumer and the brand, the consumer forms his image regarding the expectations of the brand. It is very important that the promises made by the brand meet the expectations of the consumer to meet his needs, it should be noted that a strong brand always meets the expectations of consumers and creates loyalty, which is confirmed by a high level of sales.

The quantitative characteristics of ROBI 8 include the following [15]:

1. The number of buyers attracted by the brand is calculated as the difference between the number of consumers at the moment and the number of consumers before the introduction of the brand. The criterion should be based on the reasons for the purchase of the product, namely to take into account the consumers who have purchased the product through the actions of the company aimed at the interaction of the brand with the consumer.

2. The role of the brand in shaping consumer loyalty. This criterion is estimated by the number of consumers who have refused or purchased the product through the brand. The difficulty of obtaining the results of this criterion is based on the fact that a consumer survey is probable.

3. Frequency of brand purchases. The criterion describes the number of consumers who have increased their brand value purchases through a quality brand engagement strategy with the consumer. Under this brand, the company can market other products, while high loyalty of the main product will positively affect the loyalty to new products.

4. Brand value in financial terms. This criterion evaluates the value that a brand can add to a product, without losing regular customers because of too high a price and not seem low quality to new consumers because of low cost. This criterion is evaluated against competitors.

\section{The basic results of research}

The company in the field of brand evaluation Interbrand has developed its method, which is to determine the brand multiplier by 7 criteria, the combination of which defines "Brand Strength" [12]. On the basis of expert evaluation, each of the criteria is given a certain weight, and the calculated weights influence the further construction of the S-shaped curve, but the equation of the curve is not publicly available and is the intellectual property of the company Interbrand [8].

Based on the above mentioned methodology, we propose our own conceptual model of brand value estimation (Fig. 1). The main idea behind the concept is to develop a closed system of analysis and modeling of factors that affect the reliability of the brand value and its value in obtaining the company economic value. In this case, to enhance the adaptive properties of the selected criteria, the mechanism of their action to choose alternative strategies for increasing brand value by implementing the neural network process algorithm is applied. The neural network is a factor in approximating brand value estimates to actual market conditions and serves as a backbone to clarify the input associated with the criteria for influencing factors on the brand.

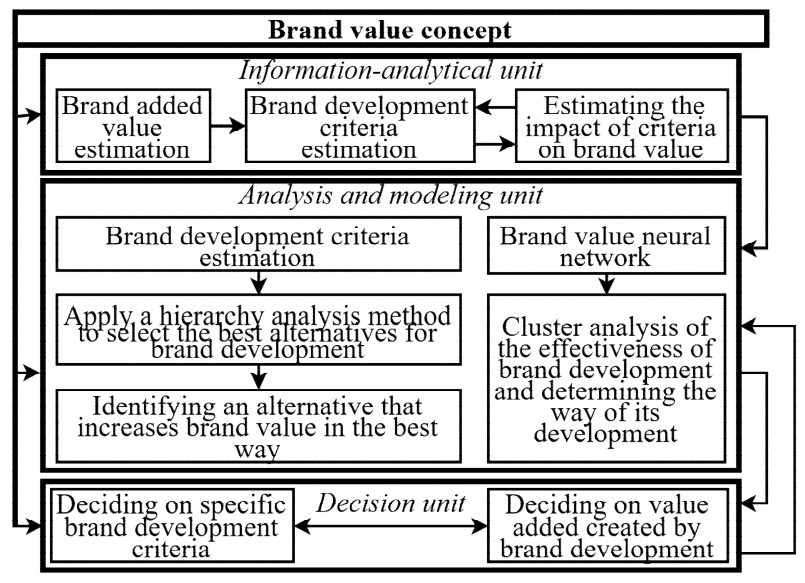

Fig. 1. The concept of evaluation brand value.

The concept, first of all, defines the basic approaches to the model of brand formation, criteria for its 
evaluation. Once the evaluation criteria have been identified and their social significance established, the analytic hierarchy process (AHP) is applied to form a better alternative to development. The Interbrand methodology takes into account many criteria, in this case, the AHP can be applied, because the values are accurate and digital, and the priority of each of them is known. According to the AHP method, local vectors of $W r$ priorities are the solution of the equation [16]:

$$
(V r-\lambda * E r) W r=0,
$$

where $E r$ is a single matrix of corresponding dimension, $\lambda$ is the proper number of the matrix of pairwise comparisons $V r$.

In the next stage, in the process of establishing the effectiveness of brand development, Kohonen neural networks are used, and the results of the analysis provide recommendations for management decisions on brand development.

The development of information technology provides an opportunity to explore various economic processes under uncertainty. In particular, to achieve the goal of this research we use specialized software product MATLAB [17], aimed at helping the user with fuzzy logic, which analyzes object of research, based on the knowledge of experts, and helps to formalize linguistic data descriptions and to justify management decisions.

Many studies in the introduction of fuzzy technology in brand management made by O. Shtovba. In particular, the article [18] provides an overview of the use of fuzzy inference to solve brand management problems, such as: modeling brand product competitiveness; optimal management of the competitiveness of the branded product with cost; determining the level of formation of the consumer capital of the enterprise, taking into account its brand; determining the feasibility of brand extension; setting the price of a new brand product; determining the similarity of two verbal trademarks; evaluating brand viral spread on social networks.

Based on the analysis of different brand assessment techniques, it is a significant advantage to be able to develop a system for managing analysis and decisionmaking processes. But it should be noted that the primary reason for the bias of the primary data lies in the collection and processing of these data by experts, due to subjectivity peer review. In turn, the V-RATIO method is almost independent of expert opinion, but the scope of this method is quite specialized and requires a lot of input to analyze the brand of the company.

NVIDIA Corporation, a computer parts manufacturer, was selected to develop a brand value model using the V-RATIO method [19]. The purpose of the study is to simulate brand management situations to strengthen it in the market and increase its value. Three alternatives were used for the study, each of which offered different percentages that determined the share of the profit generated by the brand itself: the first variant $-14 \%$; the second option is $39 \%$; the third option is $71 \%$. Thus, by calculating the sales generated by the brand; adjusted operating profit, and considering brand promotion costs, the free cash flow generated only by the brand (BFS) and the brand price (ads) were calculated (see Table 1). It was taken into account that the discount rate for the brand "NVIDIA Corporation" is $10.5 \%$. As a result of calculations by the method of V-RATIO revealed: an increase in the percentage of profit generated by the brand, leads to a stronger position of the brand in the market.

Table 1. Discounted cash flows are created only by the brand.

\begin{tabular}{|c|c|c|c|}
\hline \multirow{2}{*}{ Year } & \multirow{2}{*}{ Variant } & \multicolumn{2}{|c|}{ Indicator } \\
\cline { 3 - 4 } 2019 & & BFS, \$ million & ads, \$ million \\
\hline \multirow{3}{*}{2020} & Variant 1 & 3.71 & 3.54 \\
\cline { 2 - 4 } & Variant 2 & 28.81 & 27.44 \\
\cline { 2 - 4 } & Variant 3 & 95.49 & 90.95 \\
\hline \multirow{3}{*}{2021} & Variant 1 & 3.64 & 2.71 \\
\cline { 2 - 4 } & Variant 2 & 28.24 & 20.99 \\
\hline \multirow{3}{*}{2022} & Variant 3 & 93.58 & 69.58 \\
\cline { 2 - 4 } & Variant 1 & 3.57 & 2.30 \\
\cline { 2 - 4 } & Variant 2 & 27.67 & 17.85 \\
\cline { 2 - 4 } & Variant 3 & 91.71 & 59.17 \\
\hline \multirow{3}{*}{2023} & Variant 1 & 3.49 & 2.06 \\
\cline { 2 - 4 } & Variant 3 & 27.12 & 15.95 \\
\cline { 2 - 4 } & Variant 1 & 3.42 & 52.87 \\
\hline
\end{tabular}

However, the result made it possible to make sure that the profit share generated by the brand did not directly affect the result. A graph showing the dependence of a brand's revenue share on the brand value, if the share is between 1 percent and 100 percent, is shown in Fig. 2.

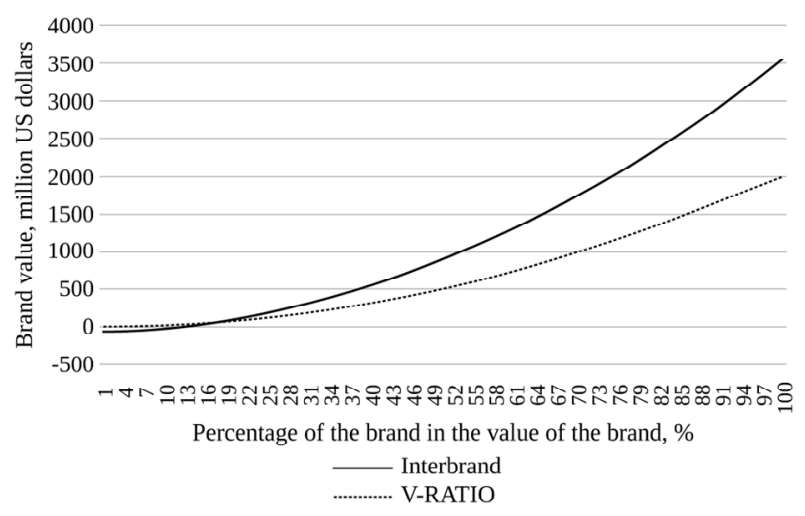

Fig. 2. Dependence of the share of revenue received by the NVIDIA Corporation brand in the value of the brand itself using the V-RATIO and Interbrand methods.

The V-RATIO brand value calculation method allows you to find out the intrinsic future value of a brand, to identify its strengths and weaknesses within the company, but it does not allow you to calculate the real market current value of the brand when it is sold. The Interbrand method was used to calculate the current market value of the NVIDIA Corporation brand, taking into account the following brand multiplier points (see Table 2). In order to compare the future intrinsic value of the brand with the current market value, the graphs are analyzed, showing the dependence of the share of the 
revenue received by the brand on the value of the brand itself (Fig. 2).

Table 2. Points of brand multiplier.

\begin{tabular}{|c|c|c|}
\hline Indicator & Maximum & Points \\
\hline Leadership & 25 & 22 \\
\hline Stability & 15 & 13 \\
\hline Market attractiveness & 10 & 10 \\
\hline Internationality & 25 & 23 \\
\hline Trends & 10 & 7 \\
\hline Support & 10 & 9 \\
\hline Protection & 5 & 4 \\
\hline Together & & 88 \\
\hline
\end{tabular}

Thus, the market value begins to exceed the internal at the share of influence of the brand on profit more than $17 \%$. After analyzing all the criteria that affect the value of the brand, it is concluded that if one or more criteria of the brand multiplier are increased, the additional value may not increase for various reasons, but the value of the brand itself will increase. Therefore, business leaders should make decisions regarding the development of brand criteria and focus on the most important for the enterprise.

To analyze the impact of different criteria on decision making, we apply the Saati hierarchy method of analysis. We construct the structure of hierarchies of influence of certain criteria on the scenarios of brand development of the company, Fig. 3.

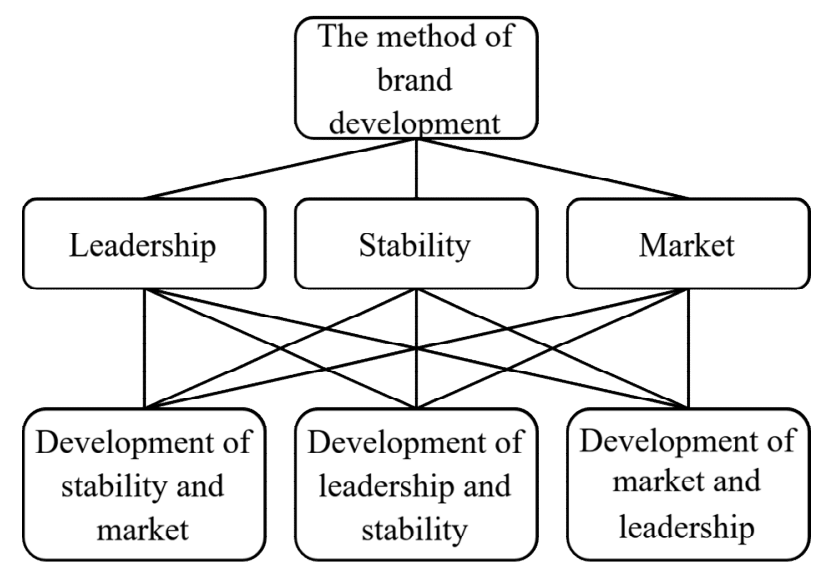

Fig. 3. The structure of the hierarchy of influence of certain criteria on the scenarios of brand development of the company.

In the case study, the number of criteria is quite large, but in practice, the number of criteria can still increase, which will complicate the task, so a system of automatic calculation in JavaScript scripting language was developed. The system is available at http://ahp.palemiya.com.

It is possible to add/remove criteria and alternatives in the system, as well as set criteria values. The system independently calculates a large number of alternatives and criteria that can be analyzed.

Calculations were made using the methodology of hierarchy analysis in the developed systems and it was found that having the resources to increase only one brand development criterion by one point, the best way to use the resources would be to develop leadership or internationality of the company (see Table 3).

Table 3. Results for each alternative.

\begin{tabular}{|c|c|}
\hline Alternatives & Result \\
\hline Leadership development & 0.1425 \\
\hline Stability development & 0.1415 \\
\hline Development of market attractiveness & 0.14 \\
\hline Development of internationality & 0.1425 \\
\hline Trend development & 0.142 \\
\hline Support development & 0.142 \\
\hline Leadership development & 0.1415 \\
\hline
\end{tabular}

Another step in evaluating brand value is to use reasonably selected parameters that, in fact, shape its value. To do this, we apply the Kohonen neural network to three input parameters that affect Intebrand brand value, namely: Brand value added, Multiplier, Advertising costs.

NVIDIA Corporation's brand value is known to be worth $\$ 26.5$ million, or $\$ 2.65$ billion. We leave the multiplier in its original form. Advertising costs will be presented in the same way as brand value added.

The "news" function creates a layer in the neural network: network $=\operatorname{newsom}\left(\left[\begin{array}{llll}0 & 2 ; & 0 & 1\end{array}\right],\left[\begin{array}{ll}5 & 6\end{array}\right]\right)$. For training in the Kohonen neural network, Fig. 4, we create an array with data corresponding to the added value of the brand, the multiplier and the cost of advertising:

$\mathrm{P}=\left[\begin{array}{llllllllllll}1.1 & 2.3 & 2.2 & 3.1 & 3.8 & 4.7 & 5.1 & 6.3 & 6.2 & 7.1 & 7.8 & 9.7 ; 0\end{array}\right.$ $\begin{array}{lllllllllllllll}3 & 4 & 10 & 10 & 12 & 14 & 15 & 15 & 19 & 17 & 18 ; & 1.1 & 1.3 & 1.2 & 2.1\end{array}$ 2.82 .72 .13 .34 .24 .14 .85 .7 ]

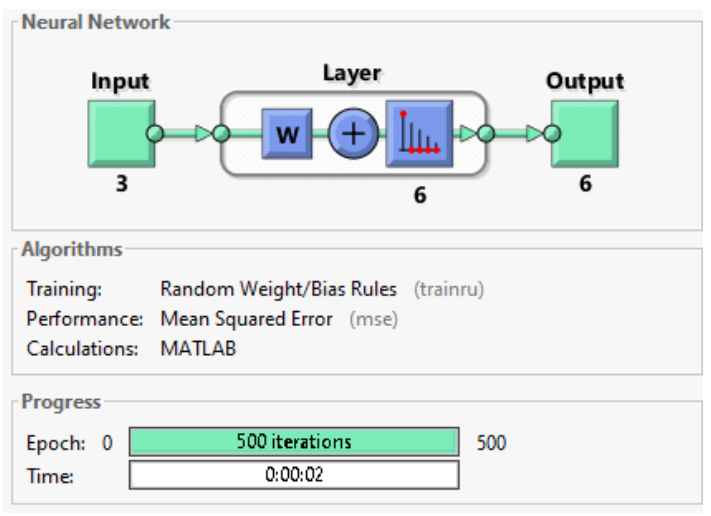

Fig. 4. Kohonen neural network.

Performing the necessary calculations in MATLAB software, we obtain an array of vectors (Fig. 5).

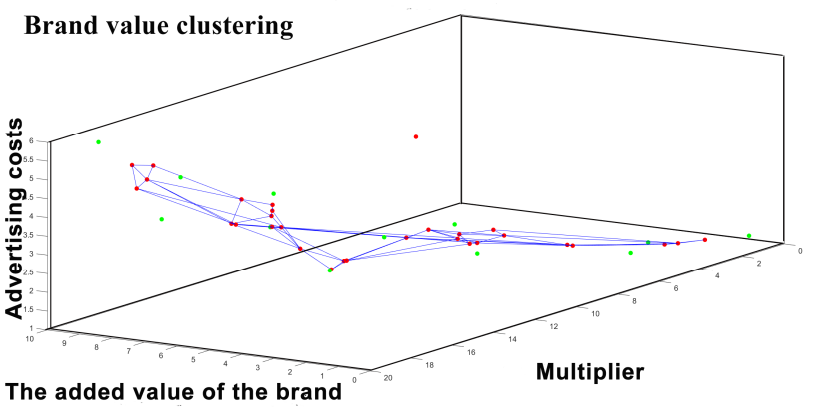

Fig. 5. Clustering the ratio of metrics that affect brand value. 
Thus, the first three input vectors belong to the first cluster, vectors 4 and 5 refer to the 3 cluster, vectors 6.7 to 4 cluster, vectors 8 and 9 refer to the 6 cluster, and vectors 10 and 100 refer to the 5 cluster. If you create a vector with NVIDIA Corporation data, we get a result that matches the vector's membership to the 6 cluster NvidiaCompanyClaster $=\operatorname{sim}($ net, $[2.6 ; 19 ; 0.4])$.

Based on this, the company needs to pay attention to advertising costs or increase value added through the brand. Multiplier indicators are balanced, but the cluster to which NVIDIA Corporation was assigned stands out for its high brand value, significant multiplier, and in contrast to cluster 5 , high advertising costs.

\section{Conclusions}

The methodology that determines brand value is based on a system that uses neural networks with elements of artificial intelligence. In turn, it allows a completely different look at the process of modeling, which improves financial performance, increases the effectiveness of management decisions. An expert system-based brand assessment methodology applies to market relations, is easy to use, and eliminates any factors that should be subjectively evaluated by an expert. Since it is versatile in application, it can be used in any sector of the economy, any area of the enterprise. The results of the new methodology calculations provide data that is useful for analyzing and making brand development decisions.

But a significant increase in the value of a brand at the current time is possible if we apply different methodological approaches to its evaluation and model different scenarios of brand development. However, using one methodology, one cannot be sure that the results of another methodology will produce a positive result. If the essence of the brand is determined and the criteria for evaluating its value are well-established, then the campaigns should have an expert system with artificial intelligence elements. In the presence of big data, the expert system makes calculations in real-time. The advantages of the expert system are obvious and their application in the field of branding has considerable prospects.

The proposed approach to assessing brand value using the new methodology makes it useful to analyze and make brand development decisions.

The use of powerful computing systems for peer review leads to the conclusion that artificial intelligence can track the dynamics of changes in this process in realtime.

\section{References}

1. D.A. Shevchenko, Reklama. Marketing. $P R$ (Advertising. Marketing. PR). (RSGU, Moscow, 2014)

2. J.R. Gregory, J. Wiechmann, Leveraging the corporate brand (NTC Business Books, Lincolnwood, 1997)
3. D. Ogilvy, P. Horgan, Confessions of an advertising man (Atheneum, New York, 1963)

4. P. Doyle, P. Stern, Marketing management and strategy (Financial Times, Prentice Hall, New York, 2006)

5. R.D. Raggio, R.P. Leone, Drivers of brand value, estimation of brand value in practice and use of brand valuation: Introduction to the special issue. $\mathrm{J}$. of Brand Management 17, 1-5 (2009). doi:10.1057/bm.2009.16

6. ISO 10668:2010 Brand valuation - Requirements for monetary brand valuation (2010), https://www.iso.org/obp/ui/\#iso:std:iso:10668:ed1:v1:ru. Accessed 29 Mar 2020

7. ISO 20671:2019 Brand evaluation - Principles and fundamentals (2019), https://www.iso.org/obp/ui/\#is o:std:iso:20671:ed-1:v1:en. Accessed 29 Mar 2020

8. Interbrand World's Most Valuable Brand's Methodology, Interbrand (2001), https://www.interbrand.com. Accessed 12 Dec 2019

9. V-RATIO (2019), http://www.v-ratio.ru. Accessed 12 Dec 2019

10. FutureBrand (2019), https://www.futurebrand.com. Accessed 12 Dec 2019

11. BBDO Consulting (2019), https://bbdo.com. Accessed 11 Dec 2019

12. BrandFinance (2019), https://brandfinance.com. Accessed 11 Dec 2019

13. About Financial Modeling Damodaran, Corporate Finance Institute (2019),

https://corporatefinanceinstitute.com/resources/quest ions/model-questions/financial-modelingdamodaran. Accessed 12 Dec 2019

14. Consor (2019), http://www.consor.com. Accessed 11 Dec 2019

15. I.I. Skorobogatykh, D.A. Chinyaeva, Sravnitelnyiy analiz suschestvuyuschih metodik otsenki stoimosti torgovoy marki (Comparative analysis of existing brand value assessment techniques). Marketing $\mathrm{v}$ Rossii i za rubezhom 5 (2003)

16. T.L. Saati, Prinyatie resheniy. Metod analiza ierarkhiy (Making decisions. Method of hierarchy analysis). (Radio i svyaz', Moscow, 1993)

17. Matlab, Fuzzy Logic Toolbox (2019), https://www.mathworks.com/products/fuzzylogic.html. Accessed 23 Dec 2019

18. O. Shtovba, Nechitki tekhnolohii v brendmenedzhmenti (Fuzzy technologies in brand management), in Materialy XLVI naukovotekhnichnoi konferentsii pidrozdiliv VNTU, Vinnytsia, 22-24 bereznia 2017 r., https://conferences.vntu.edu.ua/index.php/all-fm/allfm-2017/paper/view/2471. Accessed 19 Dec 2019

19. Income statement NVIDIA Corporation (2019), https://ru.investing.com/equities/nvidia-corpincome-statement. Accessed 23 Dec 2019 